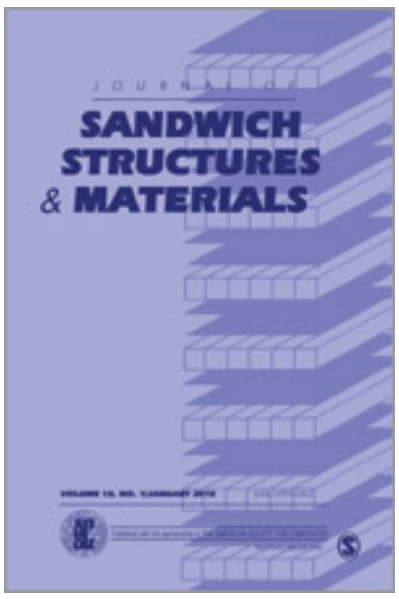

\title{
Effect of Concentrated Butt-Joints on Flexural Properties of Laminated Bamboo-Timber Flitch Beams
}

\begin{tabular}{|c|c|}
\hline Journal: & Journal of Sandwich Structures and Materials \\
\hline Manuscript ID & JSSM-21-0130.R3 \\
\hline Manuscript Type: & Standard Article \\
\hline $\begin{array}{r}\text { Date Submitted by the } \\
\text { Author: }\end{array}$ & $n / a$ \\
\hline Complete List of Authors: & $\begin{array}{l}\text { Zhang, Hexin(Johnson); Edinburgh Napier University, School of } \\
\text { Engineering and the Built Environment } \\
\text { Gharavi, Niaz; Edinburgh Napier University } \\
\text { Wong, Simon H F; Technological and Higher Education Institute of Hong } \\
\text { Kong } \\
\text { Deng, Yu; Guangxi University of Science and Technology, } \\
\text { Bahadori-Jahromi, Ali; University of West London } \\
\text { Limkatanyu, Suchart; Prince of Songkla University } \\
\text { Qiao, Yao; Pacific Northwest National Laboratory } \\
\text { Kuang, J.S.; Hong Kong University of Science and Technology, } \\
\text { Department of Civil and Environmental Engineering }\end{array}$ \\
\hline Keywords: & $\begin{array}{l}\text { laminated bamboo-timber hybrid beam, bamboo timber flitch beam, } \\
\text { butt-joint in laminated bamboo, flexural properties, bamboo-timber } \\
\text { composite beam, bio-flitch beam }\end{array}$ \\
\hline Abstract: & $\begin{array}{l}\text { This paper presents the experimental and analytical studies to } \\
\text { investigate the effect of concentrated butt-joints on the flexural } \\
\text { properties of laminated bamboo-timber flitch beam (BTFB, or bio-flitch } \\
\text { beam). The experimental results reveal that the concentrated butt-joints } \\
\text { significantly reduce the flexural strength of the BTFB. They also suggest } \\
\text { that the failure mechanism of the BTFB with or without concentrated } \\
\text { butt-joints are completely different but less evidence shows an obvious } \\
\text { effect of the butt-joints on the modulus of elasticity in bending. In } \\
\text { addition, laminated bamboo lumber with concentrated butt-joints is } \\
\text { found to be unsuitable for structural applications. The analytical } \\
\text { predictions are in close agreement with the experimental results that } \\
\text { demonstrate the potentials of the proposed analytical model as a } \\
\text { forensic investigation instrument to estimate the strength reduction of }\end{array}$ \\
\hline
\end{tabular}


the structure, if the butt-jointed laminated bamboo was, unfortunately, used in construction.

\section{SCHOLARONE \\ Manuscripts}




\title{
Effect of Concentrated Butt-Joints on Flexural Properties of Laminated Bamboo-Timber Flitch Beams
}

\author{
Hexin Zhanga , Niaz Gharavia , Simon H.F. Wong ${ }^{\mathrm{b}}$, Yu Deng, ${ }^{\mathrm{c}}$, Ali Bahadori-Jahromid, \\ Suchart Limkatanyu ${ }^{\mathrm{e}}$, Yao Qiao ${ }^{\mathrm{f}}$, J.S. Kuang \\ a School of Engineering and the Built Environment, Edinburgh Napier University, 10 Colinton Road, Edinburgh, \\ Scotland, UK, EH10 5DT \\ ${ }^{\mathrm{b}}$ Department of Construction Technology and Engineering, Technological Higher Education Institute of Hong \\ Kong, 20A Tsing Yi Road, Tsing Yi Island, New Territories, Hong Kong \\ ' School of Civil Engineering and Architecture, Guangxi University of Science and Technology, Liuzhou, China \\ 545006 \\ d Department of Civil Engineering and Built Environment, School of Computing and Engineering, University of \\ West London, London, W5 5RF, UK \\ e Department of Civil Engineering, Faculty of Engineering, Prince of Songkla University, Songkla, Thailand \\ ${ }^{\mathrm{f}}$ Pacific Northwest National Laboratory, Richland, WA, 99354, USA \\ g Department of Civil and Environmental Engineering, Hong Kong University of Science and Technology, \\ Kowloon, Hong Kong
}

\begin{abstract}
This paper presents the experimental and analytical studies to investigate the effect of concentrated butt-joints on the flexural properties of laminated bamboo-timber flitch beam (BTFB, or bio-flitch beam). The experimental results reveal that the concentrated butt-joints significantly reduce the flexural strength of the BTFB. They also suggest that the failure mechanism of the BTFB with or without concentrated butt-joints are completely different but less evidence shows an obvious effect of the butt-joints on the modulus of elasticity in bending. In addition, laminated bamboo lumber with concentrated butt-joints is found to be unsuitable for structural applications. The analytical predictions are in close agreement with the experimental results that demonstrate the potentials of the proposed analytical model as a forensic investigation instrument to estimate the strength reduction of the structure, if the buttjointed laminated bamboo was, unfortunately, used in construction.
\end{abstract}

\footnotetext{
* Corresponding author: Yu Deng E-mail address: yudenggxust@gmail.com; Co-corresponding author: Hexin Zhang, E-mail address: j.zhang@napier.ac.uk
} 
Keywords: laminated bamboo-timber hybrid beam; bamboo timber flitch beam; butt-joint in laminated bamboo; flexural properties; bamboo-timber composite beam; bio-flitch beam.

\section{Introduction}

The recent trend toward the use of more sustainable construction materials has seen a growing demand for structural timber products as building materials. Glued Laminated Timber (Glulam) is one of the most popular materials due to its excellent performance, sustainability, and aesthetic characteristics. However, increasing concerns associated with the environmental and ecological impact of deforestation highlight the need for alternatives to traditional wood materials.

In the search for non-timber forest products to substitute for wood, bamboo has emerged as a leading candidate. In particular, it is now widely recognised that bamboo in panel form may be an ideal replacement for wood in several applications owing to its properties of comparable strength to modern structural materials, easy processing and rapid growth in comparison to common trees. The rapid growth and renewability of bamboo are ideal characteristics for use in construction. However, the widespread use of raw bamboo in construction is restricted by the inherent variability in its geometric and mechanical properties, and a lack of standardisation. Engineered bamboo aims to reduce the variability of the raw material and is processed and manufactured into laminated composites; the most common form of engineered bamboo. Laminated bamboo is formed when the bamboo culm is split, planed, processed (bleached or caramelised), laminated and pressed to form the board product [1]. This process maintains both the longitudinal fibres as well as a portion of the original culm matrix.

The butt joint referred to in this study is considered as a weak cross-section of the laminated bamboo lamina. The butt-jointed laminated beams are often used in the construction of gluelaminated bridges or pre-stressed laminated timber bridges [2, 3]. As an emerging sustainable construction material, laminated bamboo has attracted increasing research attention in recent 
years [4-9]. However, laminated bamboo lumber (LBL) is produced using shorter and smaller strips of bamboo which are butt-jointed at a section to form a longer and wider lumber or board (Fig. 1). Understandably, putting the butt-joints in close proximity to each other is a much easier method of sorting the bamboo strips and a reasonable way to reduce the manufacturing cost, if the final products are not for structural use (e.g. kitchen worktops). For structural lumber, the butt-joints should be distributed evenly along the length of the lumber and in different layers, or they can be arranged in a narrow region and then finger-jointed together. However, due to lack of standardisation, there are a lot of LBL products on the market with concentrated buttjoints, concealed by the sanded, smooth, and joint-free surface layers. Even more concerningly, this is often done after being laminated with timber lumber to produce the bamboo-timber composites. If they are mistakenly used for structural purposes, the consequences could be catastrophic. During a project to develop a Laminated Bamboo-Timber Flitch Beam (BTFB, or bio-flitch beam), the wrong type of LBL was used but it accidentally provided a good opportunity to investigate the effect of the butt-joints in LBL on the structural members.

Generally, LBL with butt-joints cannot be used for structural purposes, simply because they carry no moment at the butt joint. The butt-joints reduce the flexural rigidity of the laminated beam and are considered as gaps [10]. However, in the case of a hybrid beam, these joints will perform like micro-butt-joints (Fig. 1b) and allow LBL to transfer the bending moment to some extent.

Flitch beams are widely used in different types of building structures especially when there is a need for long-span openings or heave floor loads [11-13]. The engineered bamboo materials have excellent strength-to-weight ratios which have made them excellent alternatives to replace the steel plates in the traditional flitch beams. This paper presents an investigation into the effect of the butt-joints on the flexural properties of hybrid beams made of timber and LBL. The mechanical properties of the BTFB were examined and compared with the Glulam control 
samples. The experimental results were then compared with the theoretical models proposed in this paper. The shear modulus is measured by the shear field test [14] enhanced by the photogrammetry method. Due to the multi-point/region measuring capacity, the photogrammetry method is widely used in the surface displacement measuring for timber structures [15-17]. Furthermore, three-point bending tests were conducted with smaller BTFB made from offcuts of the LBL, without any butt-joints, to compare against the hybrid beams with butt-joints.

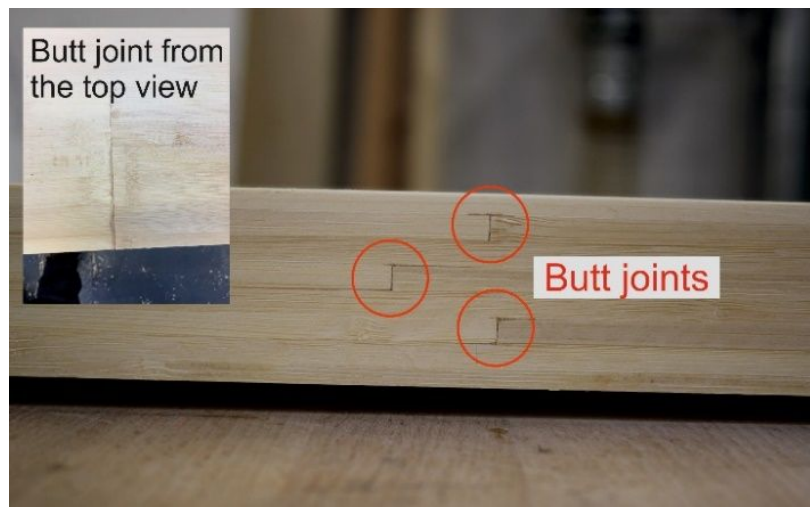

(a) Butt-joints in the laminated bamboo lumber

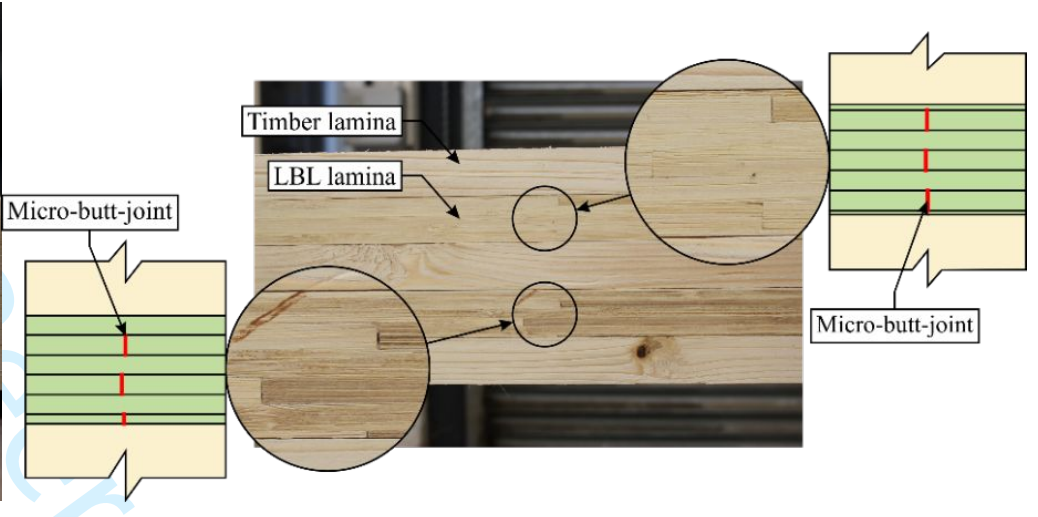

(b) The micro-butt-joints in the composite beams

Fig. 1 Butt-joint in the laminated bamboo lumber and the composite beam

\section{Butt-Joint in the Four-Point Bending Test}

\subsection{Specimens}

Three BTFB and three Glulam beams were produced and their nominal dimensions are shown in Fig. 2. The adhesive used in this experiment is Phenol Resorcinol Formaldehyde (PRF). The pressure applied during the lamination is around $90 \mathrm{kN} / \mathrm{m}^{2}$ and the indoor template is maintained at $20^{\circ} \mathrm{C}$. The LBL was made of Moso bamboo strips, originating from China, with a thickness of $5 \mathrm{~mm}$ and a width of $21 \mathrm{~mm}$. The laminated bamboo was 3 meters long and the butt-joints were located a meter away from either end. The timber was Norway spruce and structurally graded as $\mathrm{C} 24$. The manufactured beams were $142.5 \mathrm{~mm}$ wide and $178 \mathrm{~mm}$ deep. The beams were 3 meters long with a loading span of $2850 \mathrm{~mm}$. Two butt-joints were a meter apart, as shown in Fig. 3. 


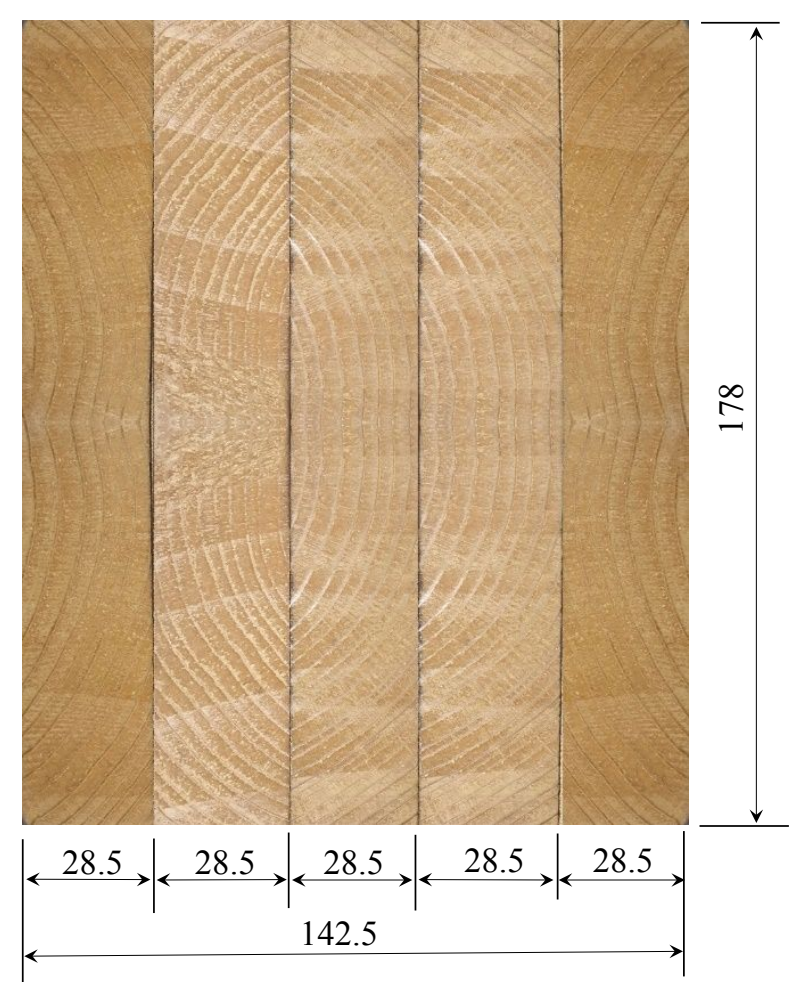

(a) Glulam beam

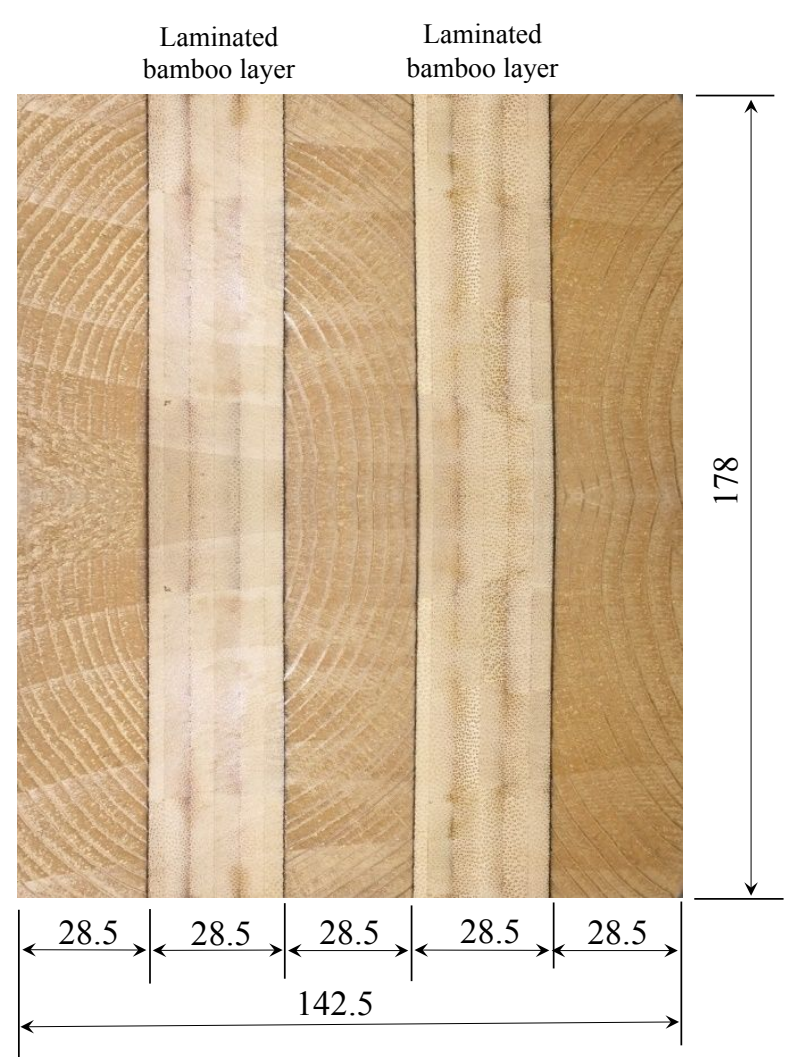

(b) Laminated hybrid beam (bio-flitch beam)

Fig. 2 Glulam and laminated hybrid beam nominal dimensions

\subsection{Experimental procedure}

The four-point bending test was conducted according to BS EN 408 [14]. Modulus of Elasticity

(MOE) and Modulus of Rupture (MOR) of the pure bending section are two commonly used material properties in the characterisation of structural materials. The following two equations specified in BS EN 408 [14] are used to compute these two properties.

$$
\begin{gathered}
M O E=\frac{a l_{1}^{2}\left(F_{2}-F_{1}\right)}{16 I\left(w_{2}-w_{1}\right)} \\
M O R=\frac{3 F a}{b h^{2}}
\end{gathered}
$$

where, $a$ is the distance between a loading position and the nearest support in a bending test, in millimetres; $l_{1}$ is gauge length for the determination of modulus of elasticity, in millimetres; $I$ is the second moment of area, in millimetres to the fourth power; $F_{2}-F_{1}$ is an increment of load in newtons on the regression line with a correlation coefficient of 0.99 or better; $w_{2}-w_{1}$ 
is the increment of deformation in millimetres corresponding to $F_{2}-F_{1} ; F$ is load, in newtons; $b$ and $h$ are the width and depth of cross-section in a bending test, in millimetres, respectively. The specimens were loaded parallel to their glue line, to ensure that each lamina experienced a similar stress distribution across the depth. Both BTFB and Glulam control samples had 80 $\mathrm{mm}$ wide bearing steel plates between the loading head and the specimen to minimise indentation. The test arrangement is illustrated in Fig. 3. The loading was applied at a rate of 6 $\mathrm{mm} / \mathrm{min}$ and the deflection of the beam was measured using six LVDTs at three points on either side of the beam, as specified by BS EN 408 (Fig. 3). The measurements of the bending test, including maximum bending moment $M_{\max }$, maximum load $F_{\max }$ and maximum deflection $W_{\max }$, are presented in Table 1 .

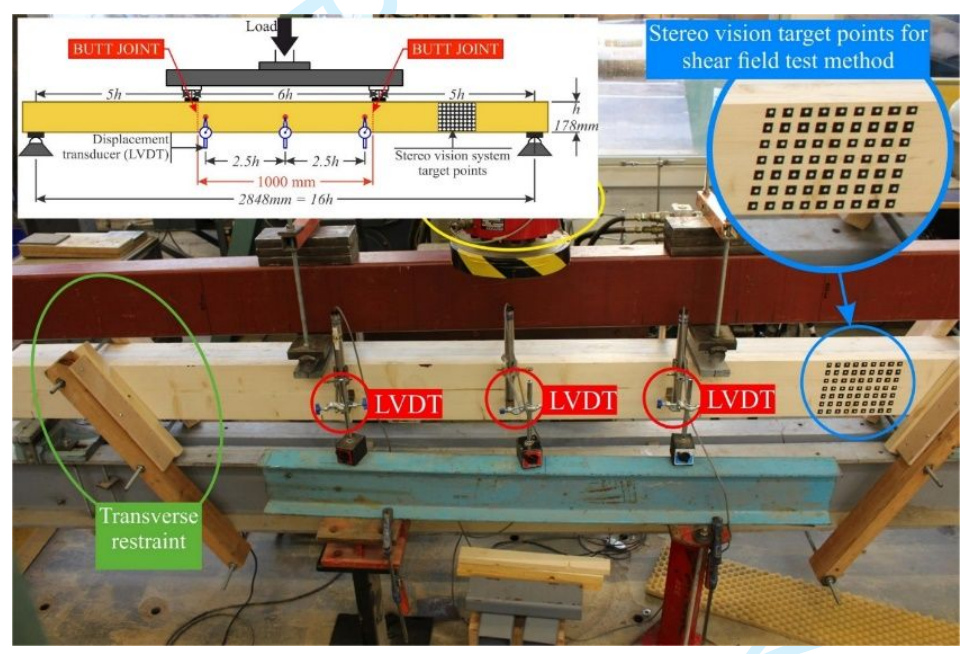

Fig. 3 Four-point bending test setup

Table 1 Four-point bending test data; GL - Glulam 


\begin{tabular}{lcccccc}
\hline \multirow{2}{*}{ Specimen } & Width & Depth & Length & $M_{\max }$ & $F_{\max }$ & $W_{\max }$ \\
\cline { 2 - 7 } & $\mathrm{mm}$ & $\mathrm{mm}$ & $\mathrm{mm}$ & $\mathrm{kNm}$ & $\mathrm{kN}$ & $\mathrm{mm}$ \\
\hline BTFB 1 & 142.3 & 178.1 & 2850 & 34.21 & 76.88 & 48.5 \\
BTFB 2 & 142.4 & 177.9 & 2850 & 33.04 & 74.25 & 55.3 \\
BTFB 3 & 141.8 & 178.0 & 2850 & 36.45 & 81.91 & 50.6 \\
GL1 & 142.3 & 177.7 & 2850 & 28.14 & 63.25 & 42.9 \\
GL2 & 142.3 & 178.0 & 2850 & 27.22 & 61.17 & 39.1 \\
GL3 & 142.1 & 177.9 & 2850 & 34.01 & 76.42 & 48.2 \\
\hline
\end{tabular}

\subsection{Four-point bending test results}

To ensure the mechanical properties of the materials used in this study are captured precisely, the four-point bending test and shear field test are employed to measure the MOE, MOR and the shear modulus $(\mathrm{G})$ of the sample beams. The measured flexural properties and the shear modulus $(\mathrm{G})$ of the tested beams can be found in Table 2 . The results of this study revealed that the BTFB exhibited $16 \%$ higher bending strength compared to the Glulam control samples despite being weakened by the butt-joint section $\left(46.04 \mathrm{~N} / \mathrm{mm}^{2}\right.$ versus $39.72 \mathrm{~N} / \mathrm{mm}^{2}$, respectively). But BTFB showed a lower $\operatorname{MOE}\left(12.97 \mathrm{kN} / \mathrm{mm}^{2}\right)$ than the control samples (13.9 $\mathrm{kN} / \mathrm{mm}^{2}$ ). Regarding the shear modulus, the BTFB demonstrated a $14 \%$ higher value than the Glulam.

A list of the test results from the previous studies is summarised in Table 2. Timber as a natural material, the mechanical properties could be influenced by many aspects, such as the speed and space they were grown, the location of the log [18], the geographic location of the forest [19], the size of the sample $[15,20]$. The density, MOE and MOR results for the C24 timber are within the range of the previous studies. The shear modulus match the previous study [15] but is significantly different from the values specified in EN 338 [21] and EN 14080 [22]. As discussed in [15], any torsion test following the current version of BS EN 408 [14] standard, the shear modulus measured could be completely wrong. 
Table 2 Four-point bending test results; GL - Glulam, CoV - coefficient of variation

\begin{tabular}{|c|c|c|c|c|c|c|}
\hline \multirow{2}{*}{\multicolumn{3}{|c|}{ Specimen }} & Density & MOE & MOR & $\mathrm{G}$ \\
\hline & & & $\mathrm{kg} / \mathrm{m}^{3}$ & $\mathrm{kN} / \mathrm{mm}^{2}$ & $\mathrm{~N} / \mathrm{mm}^{2}$ & $\mathrm{~N} / \mathrm{mm}^{2}$ \\
\hline \multicolumn{3}{|c|}{ BTFB 1} & 521.2 & 12.94 & 45.48 & 1479 \\
\hline \multicolumn{3}{|c|}{ BTFB 2} & 520.3 & 11.14 & 43.97 & 1258 \\
\hline \multicolumn{3}{|c|}{ BTFB 3} & 534.7 & 14.84 & 48.67 & 1329 \\
\hline \multicolumn{3}{|c|}{ Mean } & 525.4 & 12.97 & 46.04 & 1355 \\
\hline \multicolumn{3}{|c|}{$\mathrm{CoV}$} & $1.2 \%$ & $14.3 \%$ & $4.2 \%$ & $8.3 \%$ \\
\hline \multicolumn{3}{|c|}{$\overline{\text { GL1 }}$} & 438.3 & 12.65 & 37.58 & 1276 \\
\hline \multicolumn{3}{|c|}{ GL2 } & 449.1 & 14.82 & 36.21 & 1156 \\
\hline \multicolumn{3}{|c|}{ GL3 } & 492.3 & 14.22 & 45.36 & 1130 \\
\hline \multicolumn{3}{|c|}{$\overline{\text { Mean }}$} & 459.9 & 13.90 & 39.72 & 1187 \\
\hline \multicolumn{3}{|l|}{$\mathrm{CoV}$} & $5.1 \%$ & $8.1 \%$ & $12.4 \%$ & $6.6 \%$ \\
\hline \multirow{2}{*}{ Ref } & \multirow{2}{*}{\multicolumn{2}{|c|}{ Specimen }} & Density & MOE & MOR & $\mathrm{G}$ \\
\hline & & & $\mathrm{kg} / \mathrm{m}^{3}$ & $\mathrm{kN} / \mathrm{mm}^{2}$ & $\mathrm{~N} / \mathrm{mm}^{2}$ & $\mathrm{~N} / \mathrm{mm}^{2}$ \\
\hline \multirow{8}{*}{ [18] } & \multirow{2}{*}{ FG-BL } & Mean & 389.0 & 7.8 & 30.9 & - \\
\hline & & $\mathrm{CoV}$ & $34.0 \%$ & $1.8 \%$ & $12.3 \%$ & - \\
\hline & \multirow{2}{*}{ FG-TL } & Mean & 451.0 & 9.0 & 31.4 & - \\
\hline & & $\mathrm{CoV}$ & $33.0 \%$ & $1.2 \%$ & $7.2 \%$ & - \\
\hline & \multirow{2}{*}{$T_{h L}{ }^{a}$} & Mean & 411.0 & 8.2 & 35.4 & - \\
\hline & & $\mathrm{CoV}$ & $24.0 \%$ & $1.4 \%$ & $8.9 \%$ & - \\
\hline & \multirow{2}{*}{$\mathrm{SG}^{\mathrm{a}}$} & Mean & 444.0 & 12.0 & 48.4 & - \\
\hline & & $\mathrm{CoV}$ & $35.0 \%$ & $2.5 \%$ & $17.4 \%$ & - \\
\hline \multirow{6}{*}{ [20] } & \multirow{2}{*}{$50 \times 100^{b}$} & Mean & 455.0 & 13.7 & 52.1 & - \\
\hline & & $\mathrm{CoV}$ & $34.0 \%$ & $2.5 \%$ & $11.6 \%$ & - \\
\hline & \multirow{2}{*}{$50 \times 150^{b}$} & Mean & 444.0 & 13.0 & 52.1 & - \\
\hline & & $\mathrm{CoV}$ & $38.0 \%$ & $2.1 \%$ & $11.1 \%$ & - \\
\hline & \multirow{2}{*}{$50 \times 200^{b}$} & Mean & 426.0 & 12.2 & 49.9 & - \\
\hline & & $\mathrm{CoV}$ & $36.0 \%$ & $2.0 \%$ & $10.3 \%$ & - \\
\hline \multirow{6}{*}{ [19] } & \multirow{2}{*}{ North ${ }^{\mathrm{c}}$} & Mean & 449.0 & 11.2 & 36.4 & - \\
\hline & & $\mathrm{CoV}$ & $13.0 \%$ & $29.2 \%$ & $37.0 \%$ & - \\
\hline & \multirow{2}{*}{ West ${ }^{c}$} & Mean & 436.8 & 12.4 & 42.6 & - \\
\hline & & $\mathrm{CoV}$ & $10.6 \%$ & $24.9 \%$ & $32.0 \%$ & - \\
\hline & \multirow{2}{*}{ East c } & Mean & 441.0 & 12.2 & 42.0 & - \\
\hline & & $\mathrm{CoV}$ & $10.6 \%$ & $24.9 \%$ & $34.1 \%$ & - \\
\hline & $95 \times 95 b$ & Mean & - & - & - & 1032 \\
\hline & & $\mathrm{CoV}$ & - & - & - & $8.9 \%$ \\
\hline [15] & $45 \times 05 \mathrm{~b}$ & Mean & - & - & - & 1109 \\
\hline & & $\mathrm{CoV}$ & - & - & - & $0.77 \%$ \\
\hline & & Mean & - & - & - & 1308 \\
\hline
\end{tabular}




\begin{tabular}{|c|c|c|c|c|c|c|}
\hline & $75 \times 255^{b}$ & $\mathrm{CoV}$ & - & - & - & $2.13 \%$ \\
\hline & \multirow{2}{*}{$45 \times 170^{b}$} & Mean & - & - & - & 1367 \\
\hline & & $\mathrm{CoV}$ & - & - & - & $1.13 \%$ \\
\hline & \multirow{2}{*}{$45 \times 195^{b}$} & Mean & - & - & - & 1112 \\
\hline & & $\mathrm{CoV}$ & - & - & - & $0.37 \%$ \\
\hline [23] & $45 \times 100^{b}$ & Mean & - & - & - & 760 \\
\hline \multirow[t]{2}{*}{ Ref } & \multirow{2}{*}{\multicolumn{2}{|c|}{ Class }} & Density & MOE & $f_{\mathrm{m}, \mathrm{k}}$ & $\mathrm{G}$ \\
\hline & & & $\mathrm{kg} / \mathrm{m}^{3}$ & $\mathrm{kN} / \mathrm{mm}^{2}$ & $\mathrm{~N} / \mathrm{mm}^{2}$ & $\mathrm{~N} / \mathrm{mm}^{2}$ \\
\hline [21] & C24 & & 420.0 & 11.0 & 24.0 & 690 \\
\hline \multirow{2}{*}[22]{} & GL24c & & 400.0 & 11.0 & 24.0 & 650 \\
\hline & GL24h & & 420.0 & 11.5 & 24.0 & 650 \\
\hline
\end{tabular}

a FG: fast-grown stand; BL: butt-logs; TL: top-logs; ThL: thinning stand; SG: slow-grown stand.

${ }^{b}$ Dimension of the sample cross-section in mm.

${ }^{c}$ Geographic regions of sub-samples from Technische Universität München

The C24 timber lumbers were purchased from a commercial supplier. Their mechanical properties may have a large variation and are normally higher than the standard stiffness and strength. Thus, the mechanical properties of the C24 GL beams were evaluated with four-point bending tests to obtain their actual mechanical properties. It is not appropriate to use the data from the previous studies or the standard values from or the Eurocodes for the comparison study.

\subsection{Deformation behaviour of the tested beams}

Fig. 4 compares the typical load and deflection relationship for the BTFB. The flexural behaviour of the hybrid beams with the butt-joint is very similar to the Glulam beams. This behaviour initiated with linear elastic deformations with subtle nonlinearity before a brittle failure. The load at the rupture for the BTFB was higher than the Glulam beams but not significantly.

Fig. 5 shows the typical load-deflection graph for the BTFB, where the maximum values are highlighted. 


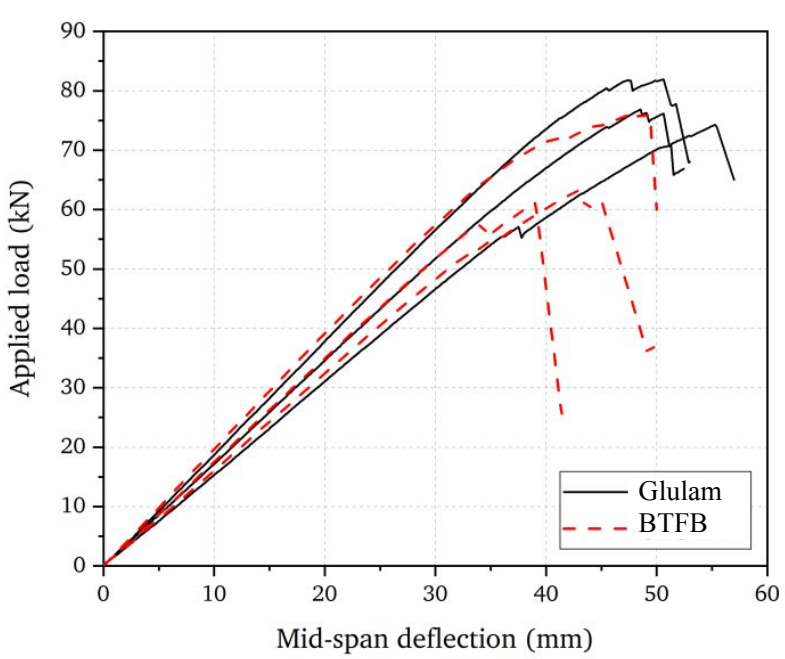

Fig. 4 Load-deflection of the tested beams in four-point bending test

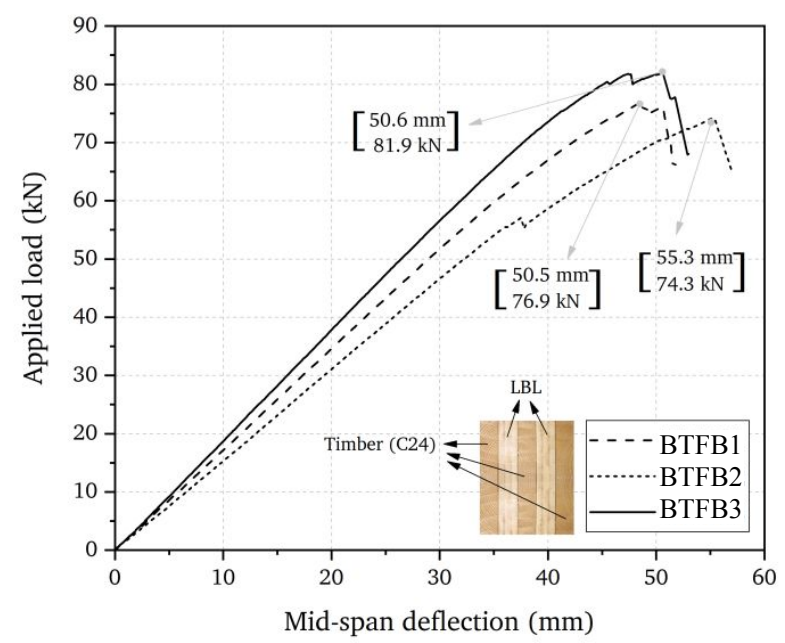

Fig. 5 BTFB load-deflection curves

\subsection{Failure analysis}

The mode of failure was similar for all the BTFB. The fracture started at the butt-joint in the tension surface and was followed by the fracture of the outer timber laminae. No compression failure nor delamination was observed. Micro-cracking sounds were audible before the failure. The failure images of BTFB 3 are shown in Fig. 6, highlighting the weakness induced by the butt-joints. Thus, using butt-jointed laminated bamboo for structural applications is not advised.

The Glulam samples experienced a similar failure pattern; a brittle failure at the tension surface, but delamination was also observed (Fig. 7).

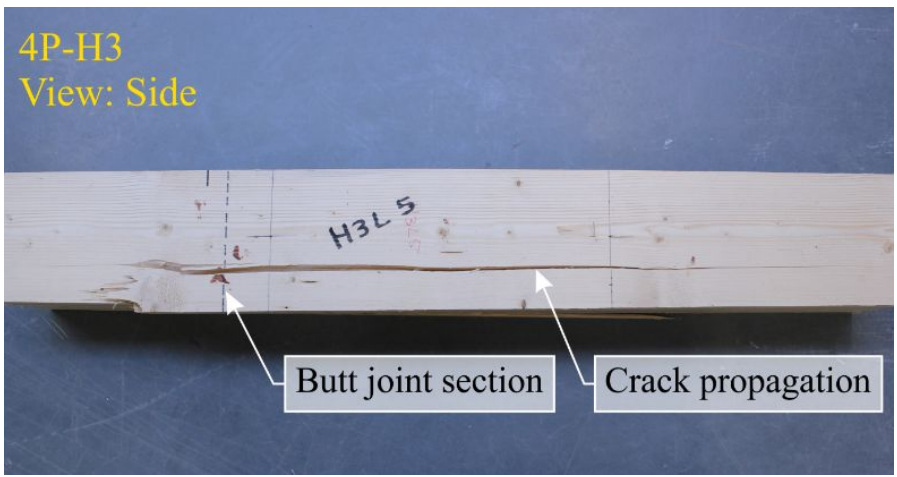

(a) Front view

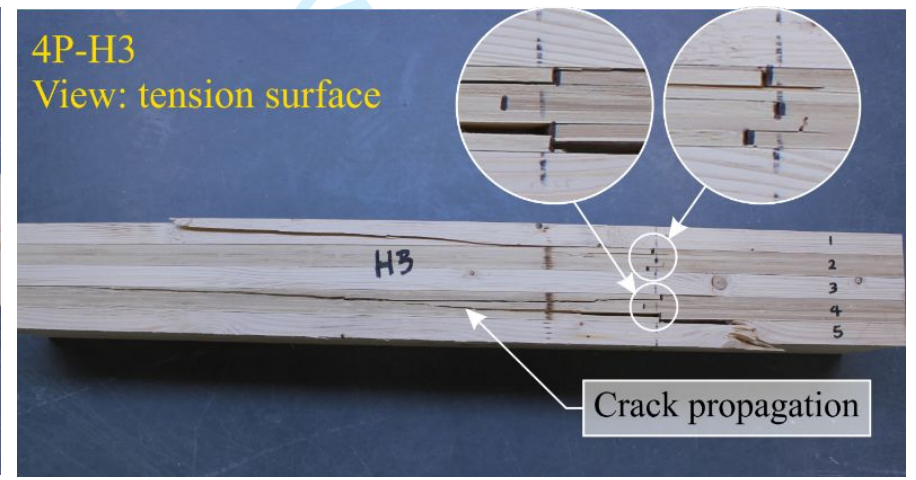

(b) Tension surface

Fig. 6 BTFB 3 failure observations 


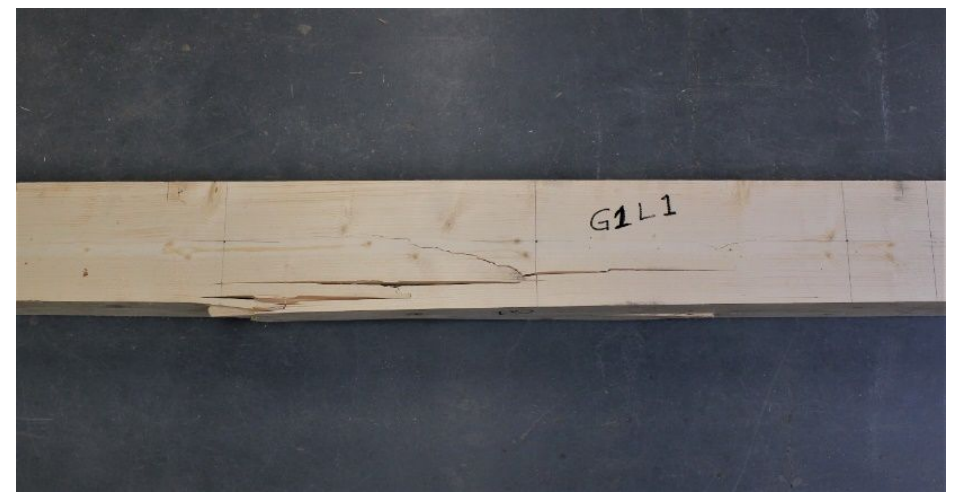

(a) Front view

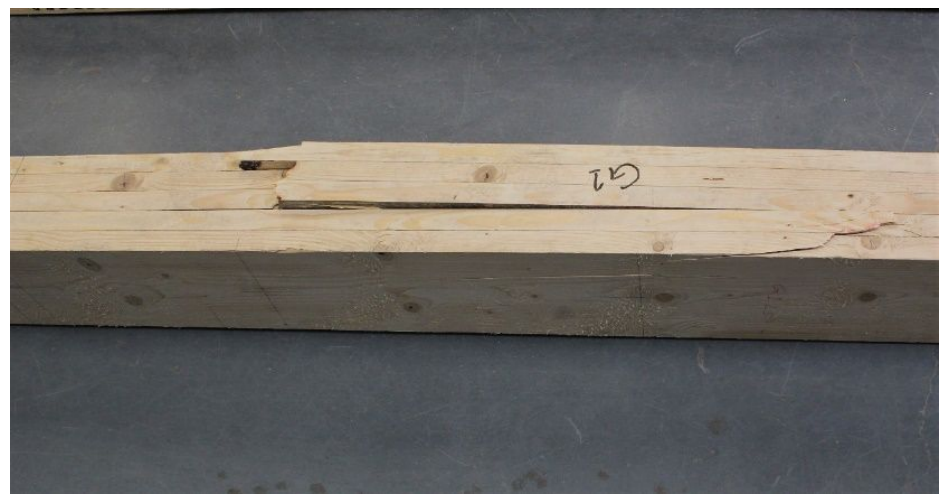

(b) Tension surface

Fig. 7 Glulam beam failure observations

\section{Three-point Bending Test on Samples Without Butt-Joints}

The three-point bending test samples were produced from the offcuts of the remaining laminate bamboo and timber materials. The laminated bamboo components were inspected to ensure no butt-joints were included. Six specimens were prepared with the following dimensions: 142.5 $\mathrm{mm}$ wide, $88 \mathrm{~mm}$ deep and a meter long. The loading span was $880 \mathrm{~mm}$ long as illustrated in Fig. 8.

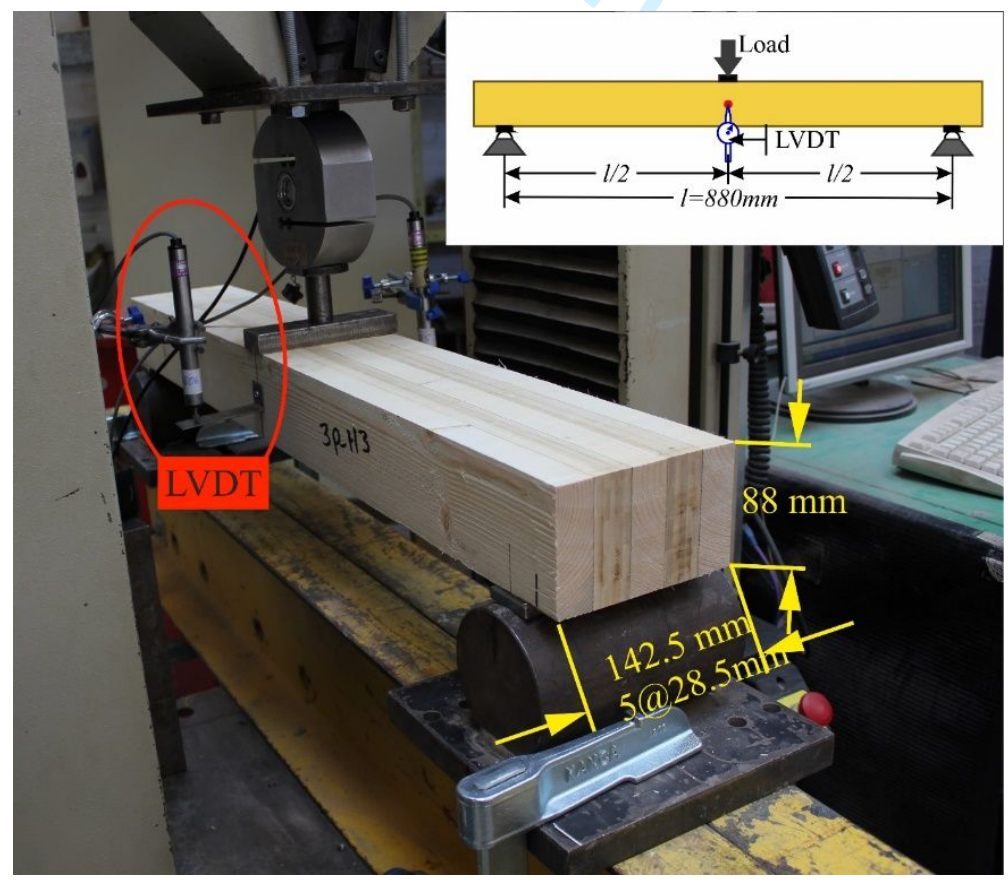

Fig. 8 Three-point bending test setup for BTFB 
MOE and MOR of the specimens, in a three-point bending test, were calculated using Eq. (3) and Eq. (4), respectively.

$$
\begin{aligned}
& M O E=\frac{F^{\prime} l^{3}}{4 \Delta^{\prime} b h^{3}} \\
& M O R=\frac{3 F_{\max } l}{2 b h^{2}}
\end{aligned}
$$

Where $F^{\prime}$ is the load at the proportional limit and $\Delta^{\prime}$ is the deflection at mid-length at the limit of proportionality.

\subsection{Four- and three-point bending test comparison}

The MOE and MOR determined using the three-point bending test can be found in Table 3 . Based on these results, BTFB without butt-joints performed significantly better in terms of bending strength compared to the Glulam control samples. The measured MOR for the BTFB without butt-joints was $72.60 \mathrm{~N} / \mathrm{mm}^{2}$ compared to $46.04 \mathrm{~N} / \mathrm{mm}^{2}$ for the BTFB with butt-joints and $39.72 \mathrm{~N} / \mathrm{mm}^{2}$ for the Glulam control samples.

The MOE in the three-point and four-point bending tests cannot be compared directly as, in the three-point bending test, the shear effect and the indentation of the loading head were neglected. These deficiencies mean the determined values are an underestimation [24]. The four-point bending test, on the other hand, gives a better estimation of the flexural modulus due to measuring the displacement in the shear free span. The measured MOE for BTFB in the threepoint bending test $\left(\mathrm{MOE}_{3 \mathrm{P}}=8.14 \mathrm{kN} / \mathrm{mm}^{2}\right)$ is well below the measured values in the four-point bending test with butt-joints $\left(\mathrm{MOE}_{4 \mathrm{p}}=12.97 \mathrm{kN} / \mathrm{mm}^{2}\right)$. Considering that the $\mathrm{MOE}_{4 \mathrm{p}}(\mathrm{MOE}$ of the four-point bending test) is calculated using the joint-free middle section, it should not be compared with $\mathrm{MOE}_{3 \mathrm{p}}$ (MOE of the three-point bending test). Therefore, it is difficult to evaluate the effect of the butt-joints on the MOE in bending thus further study is required. 
Table 3 Comparison of the four-point bending test (with butt-joint) and three-point bending test (without butt-joint)

\begin{tabular}{|c|c|c|c|c|}
\hline \multirow{3}{*}{ Specimen } & \multicolumn{2}{|c|}{ Four-point bending } & \multicolumn{2}{|c|}{ Three-point bending } \\
\hline & MOE & MOR & MOE & MOR \\
\hline & $\mathrm{kN} / \mathrm{mm}^{2}$ & $\mathrm{~N} / \mathrm{mm}^{2}$ & $\mathrm{kN} / \mathrm{mm}^{2}$ & $\mathrm{~N} / \mathrm{mm}^{2}$ \\
\hline$\overline{\mathrm{BTFB}} 1$ & 12.94 & 45.48 & 8.13 & 73.45 \\
\hline BTFB 2 & 11.14 & 43.97 & 7.37 & 67.45 \\
\hline BTFB 3 & 14.84 & 48.67 & 8.92 & 76.91 \\
\hline Mean & 12.97 & 46.04 & 8.14 & 72.60 \\
\hline
\end{tabular}

\subsection{Failure Mechanism of the BTFB in three-point bending}

The failure of the specimen in the three-point bending test, i.e. without butt-joints, was noticeably different from the four-point bending test results. The outer timber laminae failed first, followed by the middle timber lamina failure (Fig. 9a). Finally, the laminated bamboo failed after all the timber laminae fractured (Fig. 9b). Looking into the load-deflection curves presented in Fig. 10, the BTFB without butt-joints showed signs of plastic behaviour, although this could be due to the individual failure of each bamboo strip.

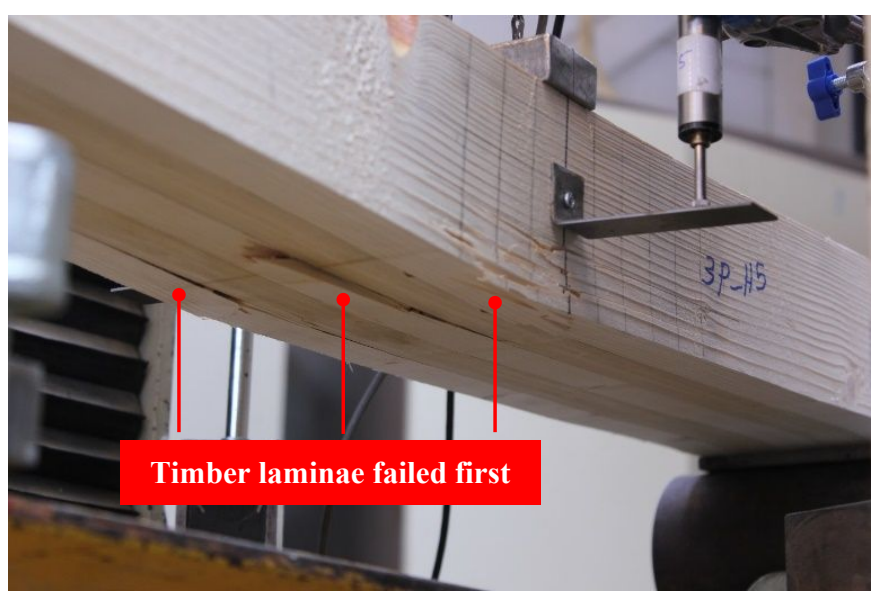

(a) Timber laminae failure first

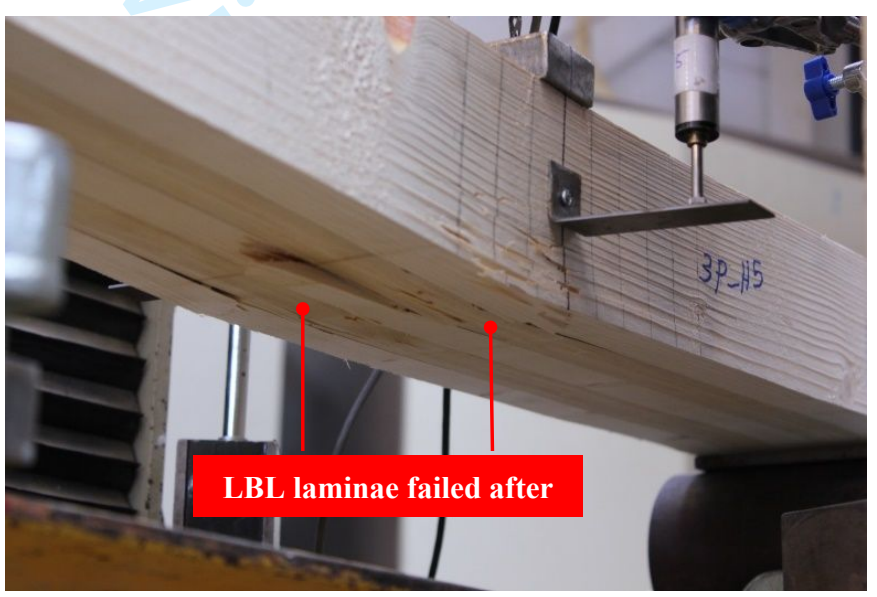

(b) LBL laminae failure after

Fig. 9 Three-point bending failure observations 


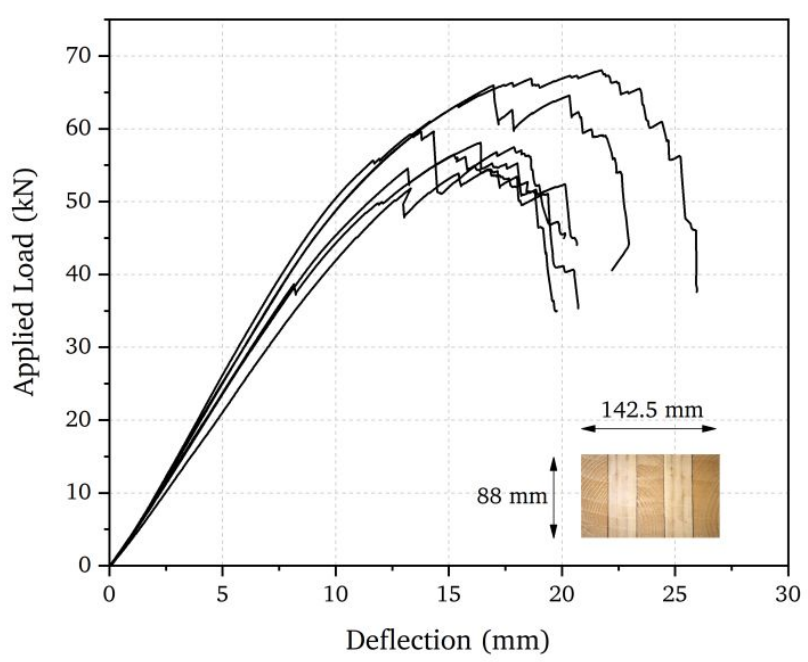

Fig. 10 Three-point bending test load-deflection curves

\section{Analytical Study}

\subsection{Prediction of the damaged length}

To investigate the effect of the butt-joint on the flexural properties of the BTFB, an analytical model developed by Jaeger and Bakht [10] was adopted. For modelling simplicity, it is assumed that the cross-section is fully butt-jointed and the faces of the joints are not in contact at this section. Based on this assumption, the laminated bamboo lamina carries no moment at the butt-joint. Therefore, the effective second moment of area (I) in this section reduces to only the second moment of area of the timber laminae. Moving away from the joint, the horizontal shear stresses which act on the vertical faces that are glued to the adjacent laminae develop flexural moment as illustrated in Fig. 11.

The horizontal equilibrium is valid for any part of the cross-section. Thus, the horizontal shear forces at both sides of each LBL lamina equals the developed moment at the section (Eq. (5)).

$$
\sigma_{d e v} b h=2 \tau_{d e v} x h
$$

where $\sigma_{d e v}$ and $\tau_{d e v}$ are, respectively, the developed bending and shear stresses at any section spaced $x$ from the butt-joint, $b$ and $h$ are the thickness and height of the LBL lamina, respectively. 


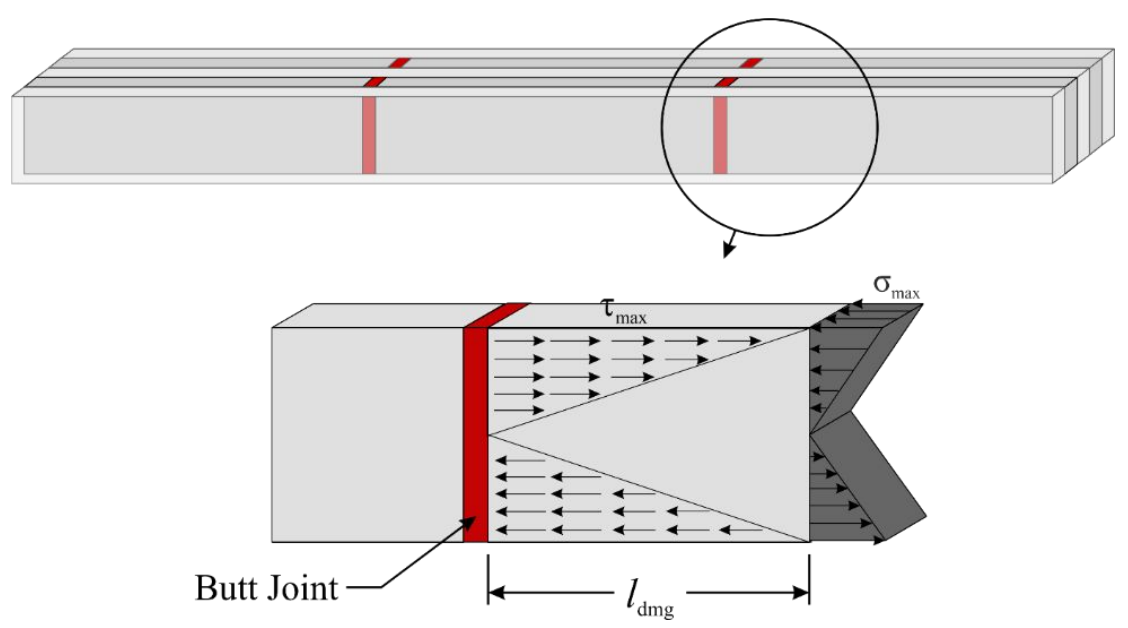

Fig. 11 Developed shear and flexural stresses in the damaged length

The bending stress in the LBL at $l_{d m g}$ distance away from the butt-joint are distributed normally with a maximum $\sigma_{\max }$ at the outermost layer. However, within the distance of $l_{d m g}$ from the butter-join, this bending moment cannot be transferred from one side of the butt-joint to another side. Instead, the bending moment is transferred through the surface shear between the LBL and the timber lumber. This shear force is linearly distributed from the neutral axis to the top and bottom of the beam. At the neutral axis, the shear force should be zero, as both LBL and timber fibres are not stretched or compressed at the neutral axis. The maximum shear force $\tau_{\max }$ occurs at the outermost layer.

According to Eq. (5), the effect of the butt-joint is negligible when the maximum bending moment of the beam equals the maximum shear stress (Fig. 11). The distance at which the effect of the butt-joint disappears is referred to here as the 'damaged distance' and denoted by $l_{d m g}$. Substituting $l_{d m g}$ with $x$ in Eq. (5) gives the damaged distance as the effect of the buttjoint (Eq. (6)).

$$
l_{d m g}=\frac{\sigma_{\max } b}{2 \tau_{\max }}
$$


Regarding the shear stress, the bond between two adjacent laminae is the only source of the shear stress. The maximum shear strength of PRF adhesive is taken from the literature [25]. Using the beam theory, the maximum flexural stress in the laminated beam can be determined using Eq. (7).

$$
\sigma_{\max }=\frac{P a E_{b} \bar{y}}{E_{c} I_{c}}
$$

where $P$ and $a$ are the maximum applied load and the distance of the loading point to the nearest support, respectively. $E_{b}$ is the modulus of elasticity of the laminated bamboo, $E_{c}$ and $I_{c}$ are the modulus of elasticity and moment of inertia of the hybrid beam, respectively.

Based on the Eq. (6), the LBL laminae develop their maximum flexural rigidity at a distance of $l_{d m g}$ from the butt-joints. The effective moment of inertia of the hybrid beam considered only the timber laminae (3I) at the location of the butt-joint and increases linearly to its full value $(5 I)$ at the distance of the damaged length from the butt-joint.

Fig. 12 illustrates the distribution of the effective moment of inertia along the hybrid beam. The calculated damaged length based on the maximum shear and flexural stress of the LBL laminae is given in Table 4.

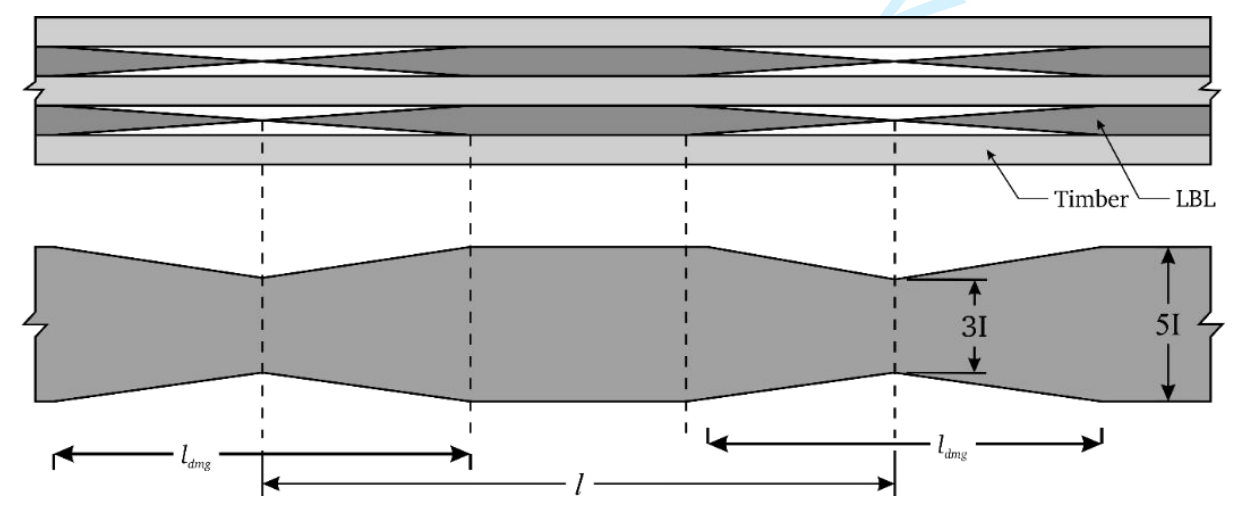

Fig. 12 Effective moment of inertia along the hybrid beam 
Table 4 Weakened zone estimation for hybrid beams

\begin{tabular}{lccc}
\hline Beam & $\sigma_{\max }$ & $\tau_{\max }$ & $l_{d m g}$ \\
\cline { 2 - 4 } & $\mathrm{N} / \mathrm{mm}$ & $\mathrm{N} / \mathrm{mm}$ & $\mathrm{mm}$ \\
\hline BTFB 1 & 34.45 & 9.87 & 248 \\
BTFB 2 & 38.69 & 9.87 & 279 \\
BTFB 3 & 32.13 & 9.87 & 230 \\
\hline
\end{tabular}

\subsection{Deflection at the butt-joint}

Fig. 13 shows the schematic illustration of the beam for the deflection analysis. Referencing Table 4, it is assumed that the damaged length is $l_{d m g}=250 \mathrm{~mm}$ and the second moment of area develops linearly away from the location of the butt-joint. However, for simplicity, the beam is assumed to have a constant moment of inertia throughout its length. According to the recommendations of Jaeger and Bakht [10], this constant moment of inertia can be assumed as following (Eq. (8)).

$$
\begin{gathered}
I_{e}=k N I \\
k=\frac{1}{2 N}\left\{\lambda \cdot \ln \left(\frac{N}{N-1}\right)+\frac{0.5-\lambda}{N}\right\}^{-1}
\end{gathered}
$$

where $k$ is the reduction factor, $N$ is the total number of laminae, $\lambda=\frac{l_{d m g}}{l}$, and $l$ is the longitudinal distance between two butt-joints.

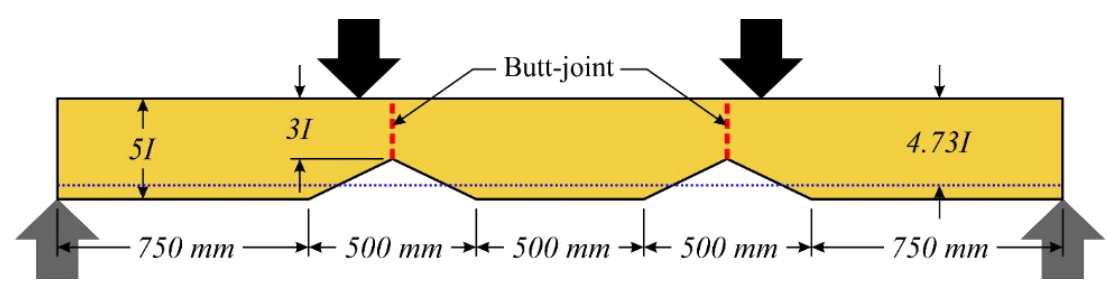

Fig. 13 Simplified beam for deflection analysis

Jaeger and Bakht [10] studied the reduction factor $(k)$ in different cases and proposed a simplified equation which states that, for $\lambda$ between 0 and 1 , the reduction factor can be 
determined as:

$$
k=\frac{N-\lambda}{N}
$$

The simplified beam is also prismatic and simply supported with two loading points. The deflection of the beam in the mid-span was calculated using the Euler-Bernoulli beam theory (Eq. (11)).

$$
\delta_{x}=\frac{P a\left(3 L x-3 x^{2}-a^{2}\right)}{12 E_{c} I_{e}} \quad a<x<\frac{L}{2}
$$

where $P$ is the total applied load, $E_{c}$ is the MOE in bending of the hybrid beam, $L$ is the beam span, $a$ is the distance between the loading point and the adjacent support, and $x$ is the distance of the deflection measuring point to the adjacent support. $\lambda=1$ was assumed to obtain more conservative predictions for the deflection of the beam. The experimental results validate the findings of the calculated values with excellent agreement.

Fig. 14 compares the measured deflection with the calculated values. The result of this analysis implies that the effect of butt-joints in the hybrid beam is considerable and cannot be ignored in the calculations. This impact most obviously presents itself in the reduced flexural rigidity and strength, despite the fact that butt-jointed laminae are rigidly constrained with adjacent laminae. 


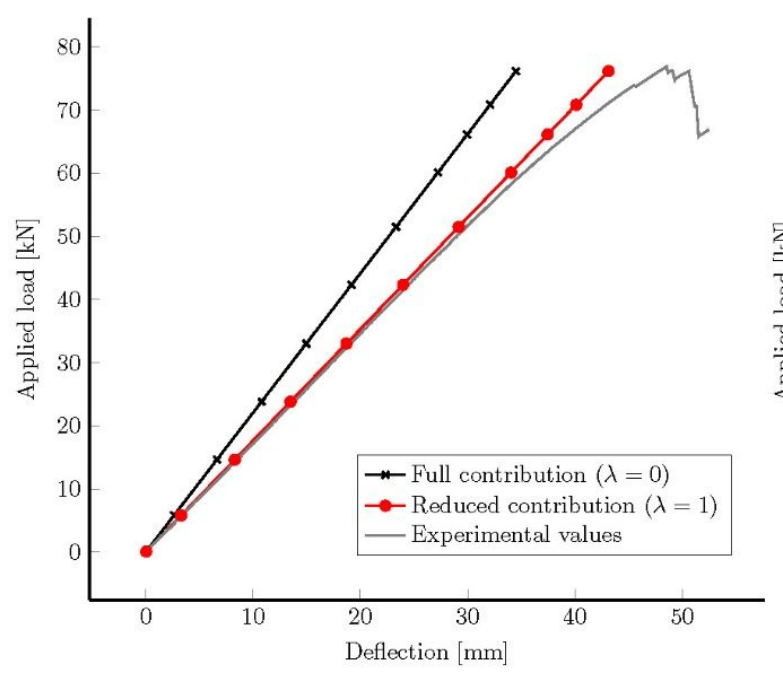

(a) BTFB 1

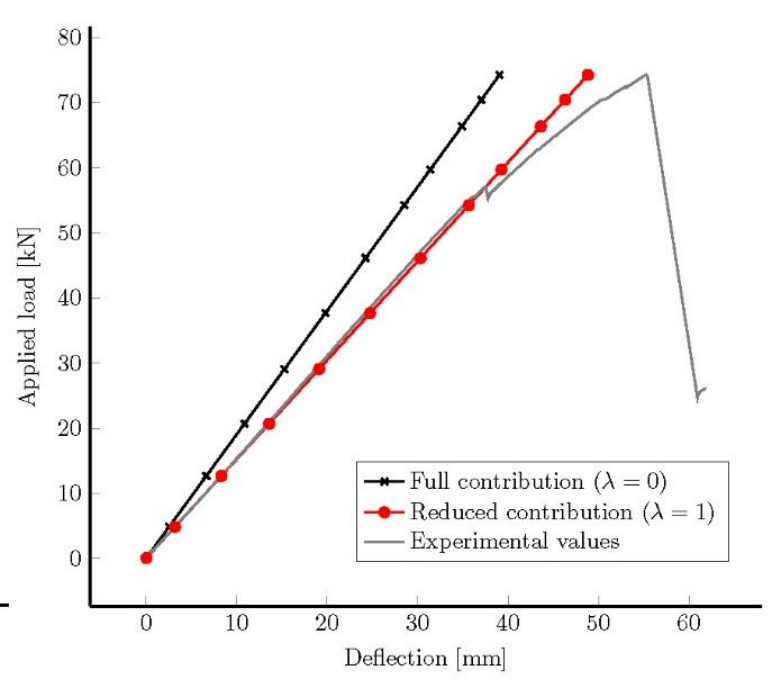

(b) BTFB 2

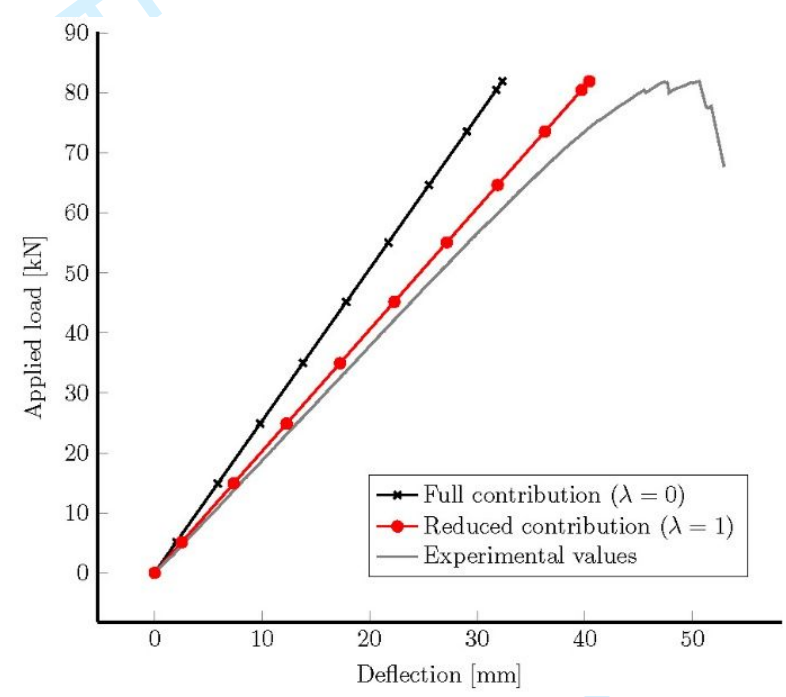

(c) BTFB 3

Fig. 14 Experimental and calculated beam deflection

\section{Conclusions}

This paper investigated the effect of butt-jointed Laminated Bamboo Lumber (LBL) on the basic mechanical properties of the Laminated Bamboo-Timber Flitch Beam (BTFB). LBL is often manufactured with concealed butt-joints to obtain longer and wider boards, which can be problematic if not identified and examined.

Therefore, a series of experiments were conducted to evaluate this effect to determine the impacts on the mechanical properties. Three BTFB which contain butt-joints and three Glulam control samples were manufactured and tested in the laboratory of Edinburgh Napier 
University. In addition, six small size beams without butt-joints were prepared using the offcut materials and were tested by a three-point bending test.

The results of these experiments revealed that the butt-joint can potentially reduce the bending strength of the BTFB by about $60 \%$. However, when compared to the Glulam control samples, BTFB performed comparably with respect to the mechanical properties. The bending strength of BTFB with butt-joints was $16 \%$ higher than the control samples but the bending modulus was $12 \%$ lower. The load-deflection of both beams, i.e. BTFB with butt-joints and Glulam control sample, were similar. Therefore, manufacturing BTFB with concentrated butt-jointed will weaken the structural properties of the beam despite the laminated bamboo itself has excellent mechanical properties.

The butt-joint also weakened the section and initiated failure. The beams started to fracture at the location of the butt-joints which then propagated to the adjacent timber laminae. However, in the BTFB without butt-joints, the timber laminae were the first to fracture followed by the laminated bamboo.

The modulus of elasticity in bending of the beam was not affected by the butt-joints according to the test result but it was calculated using the elastic region during the test. The butt-joints effect may not have a large impact within the elastic region. The load-deflection graphs also showed that the BTFB with butt-joints failed right after the elastic region.

An analytical model to predict the damaged length caused by the butt-joints was proposed. The analytical predictions are in good agreement with experimental results when an appropriate correction factor is applied.

\section{Acknowledgements}

The authors would like to express their special gratitude to the support from the Royal Academy of Engineering-Visiting Professor (VP2021\7\12), Royal Academy of Engineering- 
Industrial Fellowship (IF $\backslash 192023$ ), British Council (UK-China-BRI Countries Education Partnership Initiative), Scottish Founding Council-Innovation Voucher: Bamboo-Timber Composite Materials for Structural Use, Lawrence Ho Research Fund, the National Nature Science Foundation of China (51768008), China Postdoctoral Science Foundation Project (2017M613273XB), Nature Science Foundation of Guangxi Zhuang Autonomous Region (2019JJA160137), and Liuzhou Scientific Research and Technology Development Plan (2017BC40202).

\section{References}

[1] Mahdavi M, Clouston P, Arwade S. Development of Laminated Bamboo Lumber: Review of Processing, Performance, and Economical Considerations. Journal of materials in Civil Engineering. 2011;23:1036-42.

[2] Ekholm K, Crocetti R, Kliger R. Stress-laminated timber decks subjected to eccentric loads in the ultimate limit state. Journal of Bridge Engineering. 2013;18:409-16.

[3] Dansoh AB, Koizumi A, Hirai T. Compressive and tensile properties of a butt-jointed lamination model. Journal of wood science. 2003;49:405-10.

[4] Chen G, Yu Y, Li X, He B. Mechanical behavior of laminated bamboo lumber for structural application: an experimental investigation. European Journal of Wood and Wood Products. 2020;78:53-63.

[5] Chen G, Wu J, Jiang H, Zhou T, Li X, Yu Y. Evaluation of OSB webbed laminated bamboo lumber box-shaped joists with a circular web hole. Journal of Building Engineering. 2020;29:101129.

[6] Cui Z, Xu M, Tu L, Chen Z, Hui B. Determination of dowel-bearing strength of laminated bamboo at elevated temperatures. Journal of Building Engineering. 2020;30:101258.

[7] Zhang H, Gharavi N, Taliercio A, Corigliano A, Deng Y, Sigrist C, et al. Development of 
laminated bamboo and timber composite beams, a state-of-the-art full-scale study, material properties and test methods. Construction and Building Materials. 2021;Submitted.

[8] Zhang H, Gharavi N, Taliercio A, Corigliano A, Deng Y, Sigrist C, et al. Development of laminated bamboo and timber composite beams, a state-of-the-art full-scale study, bambootimber hybrid beams. Construction and Building Materials. 2021;Submitted.

[9] Zhang H, Gharavi N, Taliercio A, Corigliano A, Deng Y, Sigrist C, et al. Development of laminated bamboo and timber composite beams, a state-of-the-art full-scale study, I-beam and double I-beam. Construction and Building Materials. 2021;Submitted.

[10] Jaeger LG, Bakht B. Effect of butt joints on the flexural stiffness of laminated timber bridges. Canadian Journal of Civil Engineering. 1990;17:859-64.

[11] Nabati A, Ghanbari-Ghazijahani T, Valipour HR. Innovative flitch sandwich beams with steel core under four-point bending. Engineering Structures. 2021;233:111724.

[12] Olorunnisola AO. Design of Wooden Beams. Design of Structural Elements with Tropical Hardwoods: Springer; 2018. p. 119-60.

[13] Beycan ADO, Özmertyurt G. Residential Architecture Of Botsa Rural Settlement İn Konya-Turkey.

[14] BSI. BS EN 408: 2010+ A1: 2012 Timber structures. Structural timber and glued laminated timber. Determination of some physical and mechanical properties. British Standard Institute; 2012.

[15] Gharavi N, Zhang H, Xie Y, He T. End effect on determining shear modulus of timber beams in torsion tests. Construction and Building Materials. 2018;164:442-50.

[16] Gharavi N, Zhang H. Study on the Impact of Size and Position of the Shear Field in Determining the Shear Modulus of Glulam Beam Using Photogrammetry Approach. International Journal of Structural and Construction Engineering. 2018;12:218-22.

[17] Mohamed A, Deng Y, Zhang H, Wong SHF, Uheida K, Zhang YX, et al. Photogrammetric 
evaluation of shear modulus of glulam timber using torsion test method and dual stereo vision system. European Journal of Wood and Wood Products. 2021.

[18] Kliger IR, Perstorper M, Johansson G. Bending properties of Norway spruce timber. Comparison between fast-and slow-grown stands and influence of radial position of sawn timber. Annales des sciences forestières: EDP Sciences; 1998. p. 349-58.

[19] Ranta-Maunus A. Strength of European timber: Part 1. Analysis of growth areas based on existing test results. 2009 .

[20] Vestøl GI, Høibø O, Langsethagen KG, Skaug E, Skyrud REA. Variability of density and bending properties of Picea abies structural timber. Wood Material Science \& Engineering. 2012;7:76-86.

[21] BSI. BS EN 338:2016 Structural Timber - Strength classes. British Standard Institute; 2016.

[22] BSI. BS EN 14080:2013 Timber structures — Glued laminated timber and glued solid timber — Requirements. British Standard Institute; 2013.

[23] Khokhar A, Zhang H, Ridley-Ellis D, MOORE J. The shear strength, and failure modes, of timber joists obtained from the torsion test method. Proceedings of the 11th World Conference of Timber Engineering2010. p. 20-4.

[24] Brancheriau L, Bailleres H, Guitard D. Comparison between modulus of elasticity values calculated using 3 and 4 point bending tests on wooden samples. Wood Science and Technology. 2002;36:367-83.

[25] Sinha A, Way D, Mlasko S. Structural performance of glued laminated bamboo beams. Journal of Structural Engineering. 2014;140:04013021. 